Scientific Electronic Archives

Issue ID: Sci. Elec. Arch. Vol. 15 (1)

January 2022

DOI: http://dx.doi.org/10.36560/15120221489

Article link: https://sea.ufr.edu.br/SEA/article/view/1489

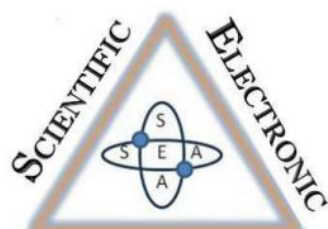

ArChives

ISSN 2316-9281

\title{
Crescimento inicial de mudas de Sapindus saponária com uso de hidrogel e lâminas de água
}

\author{
Initial growth of Sapindus saponária seedlings with the use of hydrogel and \\ water slides
}

\author{
Joelma Mendes de Carvalho \\ Universidade do Estado de Mato Grosso - Campus Cáceres \\ Daniela Soares Alves Caldeira \\ Universidade do Estado de Mato Grosso - Campus Cáceres
}

$\begin{array}{r}\text { Corresponding author } \\ \text { Carlos Luiz Vieira }\end{array}$
Universidade do Estado de Mato Grosso- Campus Tangará da Serra
carlos.luiz 12@hotmail.com

Gabriel Vinícius Batista da Silva

Universidade do Estado de Mato Grosso - Campus Cáceres

Rafael Rosa Rocha

Universidade do Estado de Mato Grosso - Campus Tangará da Serra

Isabel de Campos

Universidade do Estado de Mato Grosso - Campus Alta Floresta

Resumo. Ainda que as técnicas de produção de mudas florestais sejam bem consolidadas, há uma busca constante por alternativas de manejo que proporcionem melhor qualidade às mudas. Dentre estas, tem se destacado a adição de polímeros hidroretentores visando aumentar a capacidade de retenção de água no solo para as mudas, propiciando melhor qualidade e maior sobrevivência no campo. O presente trabalho teve por objetivo agregar informações sobre a espécie e investigar o efeito de hidrogel associado a diferentes lâminas de água no crescimento inicial de Sapindus saponária. O estudo foi conduzido no campo experimental da Universidade do Estado de Mato Grosso (UNEMAT) Campus de Cáceres-MT. O delineamento utilizado foi inteiramente casualizado em esquema fatorial, sendo duas condições (ausência e presença de hidrogel) e quatro lâminas de água (8,10,12 e 14 mm.dia-1) com quatro repetições e três plantas por unidade experimental. As avaliações procederam-se aos 120 dias após a semeadura, onde foram verificadas as seguintes características: altura de planta, diâmetro de coleto, número de folhas, além de massa seca e massa fresca da parte aérea e raiz e índice de qualidade de Dickson (IQD). As mudas de Sapindus saponária apresentaram melhor desenvolvimento quando submetidas a presença do hidrogel, mostrando significância para todas as variáveis analisadas. Em contrapartida, as diferentes lâminas de água, não apresentaram resultados promissores, se destacando significativamente apenas para a variável número de folhas. Em geral, os resultados obtidos com relação ao uso de polímeros hidrorretentores ratificam a informação que a adição de hidrogéis no substrato otimiza a disponibilidade de água, acelerando o desenvolvimento das plantas e resultando em mudas de melhor qualidade.

Palavras-chaves Espécie florestal, Polímero hidroretentor, Pantanal.

Abstract. Although forest seedling production techniques are well consolidated, there is a constant search for management alternatives that provide better quality to the seedlings. Among these, the addition of water-retaining 
polymers has been highlighted in order to increase the water retention capacity in the soil for the seedlings, providing better quality and greater survival in the field. This study aimed to gather information about the species and investigate the effect of hydrogel associated with different water depths on the initial growth of Sapindus saponária. The study was conducted in the experimental field of the University of the State of Mato Grosso (UNEMAT) Campus de Cáceres-MT. The design used was completely randomized in a factorial scheme, with two conditions (absence and presence of hydrogel) and four water depths (8,10,12 and $14 \mathrm{~mm}$.day-1) with four replications and three plants per experimental unit. The evaluations were carried out 120 days after sowing, where the following characteristics were verified: plant height, stem diameter, number of leaves, in addition to dry mass and fresh mass of shoot and root and Dickson quality index (IQD). Sapindus saponária seedlings showed better development when subjected to the presence of the hydrogel, showing significance for all analyzed variables. On the other hand, the different water depths did not show promising results, standing out significantly only for the variable number of leaves. In general, the results obtained regarding the use of water-retaining polymers confirm the information that the addition of hydrogels to the substrate optimizes water availability, accelerating plant development and resulting in better quality seedlings.

Keywords: Forest species, Water-retaining polymer, Pantanal.

\section{Introdução}

A falta de planejamento no uso dos recursos naturais, tem resultado na degradação dos ecossistemas florestais. Ademais, ação do homem sobre 0 meio ambiente, traz consequências prejudiciais a natureza. Diante disso, diferentes espécies são estabelecidas em plantios pioneiros na recuperação de áreas degradadas (SANTOS et al., 2012). Dentre elas, destaca-se à Sapindus saponária, pertencente à família Sapindaceae, conhecida popularmente como sabão-de-soldado, saboneteira e sabão-de-macaco (SOUZA \& LORENZI, 2005).

A demanda por produtos de origem florestal aumenta, levando a silvicultura a buscar alternativas que visam a obtenção de altas produtividades (BOLFE, 2014). Para que isso ocorra, é de grande necessidade o sucesso de um plantio florestal, que irá depender da escolha da espécie ideal para cada local, do objetivo do plantio e, principalmente, da qualidade das mudas a serem plantadas, que além de resistirem às condições adversas de campo, devem ser capazes de se desenvolver e exteriorizar todo o seu potencial de crescimento, tornando o replantio uma prática dispensável, dada à pequena taxa de mortalidade em campo (CARNEIRO, 1995; GOMES \& PAIVA, 2004; WENDLING \& DUTRA, 2010).

Para um bom desenvolvimento inicial das mudas é ideal levar em consideração vários fatores, entre eles o fornecimento de água e a otimização em seu uso. Para tanto, a lâmina ideal a ser adotada na irrigação em viveiros deve ser adequada às condições do local a se produzir, possibilitando às mudas o seu máximo crescimento e qualidade (GORDIN et al., 2015; SILVA et al., 2015). Além disso, o fornecimento inadequado pode diminuir consideravelmente o vigor da muda restringindo seu desenvolvimento (SCALON et al., 2001).

O estresse hídrico é uma das maiores causas de mortalidade e de deficiência de crescimento de espécies nativas em áreas degradadas, atuando em diversos processos fisiológicos das plantas. Em condições de baixa disponibilidade de água no solo, vários processos do metabolismo vegetal podem ser influenciados, como o fechamento estomático, a redução da condutância estomática, a redução da fotossíntese e a transpiração, levando ao declínio da taxa de crescimento (SCALON et al., 2001).

Os polímeros hidroretentores também chamados de hidrogéis ou polímeros retentores de água são caracterizados como produtos naturais (derivados do amido) ou sintéticos (derivados do petróleo), sendo valorizados por sua capacidade de absorver e armazenar água. Quebradiços quando secos, eles se tornam macios e elásticos depois de expandidos em água. Nesse contexto, Taylor \& Halfacre (1986) ressaltam que o polímero hidroretentor de água é comercializado com as justificativas de que, ao ser incorporado ao substrato, permite maior retenção de água e de fertilizantes, que podem lentamente ser liberados para as plantas em função dos ciclos absorção liberação.

Desse modo, a utilização de hidrogel associada a lâmina ideal de água, se mostra como alternativa de produção possibilitando a planta o seu máximo rendimento com maior eficiência no uso da água. Diante disso, o presente trabalho teve como objetivo investigar o efeito do uso de polímero hidroretentor incorporado ao substrato e associado a diferentes lâminas de água no crescimento inicial e na qualidade de mudas de Sapindus saponária.

\section{Material e Métodos}

\section{Local de condução do estudo}

O projeto foi desenvolvido na área experimental de Silvicultura da UNEMAT/ Campus de Cáceres-MT, no período de setembro de 2020 a janeiro de 2021. A região é caracterizada por duas estações bem definidas (seca no inverno e úmida no verão), temperatura média anual de $25{ }^{\circ} \mathrm{C}$ podendo alcançar $40^{\circ} \mathrm{C}$ e precipitação média de $1.396 \mathrm{~mm}$ ano-1, (SILVA et al., 2008).

\section{Tratamento e delineamento experimental \\ $O$ delineamento experimental adotado foi 0 inteiramente casualizado em esquema fatorial $2 \times 4$, sendo duas condições (ausência e presença de hidrogel) e quatro lâminas de água $(8,10,12$ e 14 $\mathrm{mm}$ dia $^{-1}$ ) com quatro repetições e 3 plantas por unidade experimental.}

\section{Produção das mudas tratos culturais}


As sementes foram adquiridas de empresa idônea e o plantio foi realizado em ambiente protegido com tela tipo sombrite $50 \%$ de coloração preta. Para a superação da dormência das sementes de Sapindus Saponária, realizou-se escarificação mecânica com lixa 120, conforme descrito por Ribeiro et al. (2009). A semeadura foi realizada diretamente nos recipientes de produção (sacos plásticos de polietileno), onde foram colocadas três sementes, o desbaste foi realizado 30 dias após a semeadura (DAS). A adubação seguiu a recomendação de Dias et al. (2006) e os tratos culturais foram realizados sempre que necessário.

\section{Metodologia de avaliação}

Para cálculo da quantidade de água a ser adicionada, afim de garantir as diferentes lâminas efetivas, se considerou o proposto por Moraes et al. (2012) conforme a equação (1), e a irrigação foi realizada diariamente de forma individualizada utilizando-se copos plásticos aferidos com o auxílio de uma proveta graduada.

$$
\begin{gathered}
\mathrm{VC}=\mathrm{mm} \times \mathrm{AT} / 1000(1) \\
\mathrm{VC}: \text { volume do Copo }(\mathrm{ml}) \\
\mathrm{mm}: \text { Lâmina de irrigação }(\mathrm{mm})
\end{gathered}
$$

AT: Área circunferência do recipiente $\left(\mathrm{mm}^{2}\right)$

As avaliações foram realizadas aos 120 DAS, sendo verificadas as seguintes variáveis: altura de planta, diâmetro de colo, número de folhas, além de massa seca e massa fresca da parte aérea e raiz e índice de qualidade de Dickson (IQD). Para tanto, se fez a utilização de régua milimetrada, da superfície do substrato até o último lançamento de folhas, paquímetro digital de precisão e contagem direta das folhas.

Em seguida, as plantas foram retiradas, lavadas e seccionadas na região do colo, separando-se a parte aérea da radicular. Posteriormente 0 material foi pesado e acondicionado separadamente em embalagens de papel Kraft, identificadas e secas em estufa, previamente aquecida a $75^{\circ} \mathrm{C}$, onde foi mantido até atingir o peso constante e posteriormente pesado em balança digital de precisão.

O cálculo do índice de qualidade das mudas foi realizado aplicando-se o modelo matemático proposto por Dickson et al. (1960) e determinado por meio da fórmula:

$$
\text { IQD=PMST/[(HT/DC) + (PMSPA/PMSR)]. }
$$

\section{Análise dos dados}

As médias obtidas para cada variável foram submetidas à análise de variância e comparadas pelo teste $\mathrm{F}$ e regressão a $5 \%$ de probabilidade usando o programa SISVAR (FERREIRA, 2011).

\section{Resultados e discussões}

Os resultados da análise de variância do crescimento das mudas (Tabela 1), mostraram diferenças estatisticamente significativas ao fator hidrogel, para as variáveis diâmetro do caule, número de folhas e altura, exceto para a variável altura/diâmetro de colo.

Tabela 1- Resumo da análise de variância e médias das variáveis altura da parte aérea $(H)$, diâmetro de colo (DC), número de folhas (NF) e relação altura/diâmetro de colo (H/DC) de mudas de Sapindus saponária avaliados aos 120 DAS.

Tabela 1. Resumo da análise de variância e médias das variáveis altura da parte aérea (H), diâmetro de colo (DC), número de folhas (NF) e relação altura/diâmetro de colo (H/DC) de mudas de Sapindus saponária avaliados aos 120 DAS.

\begin{tabular}{ccccc}
\hline Variável & $\mathrm{H}(\mathrm{cm})$ & $\mathrm{DC}(\mathrm{mm})$ & $\mathrm{NF}$ & $\mathrm{H} / \mathrm{DC}$ \\
\hline Hidrogel & $45,04^{* *}$ & $47,63^{* *}$ & $16,95^{* *}$ & $1,90 \mathrm{NS}$ \\
Lâminas & $0,24 \mathrm{NS}$ & $0,67 \mathrm{NS}$ & $3,45^{*}$ & $0,58 \mathrm{NS}$ \\
$\mathrm{H}^{*} \mathrm{~L}$ & $0,96 \mathrm{NS}$ & $0,88 \mathrm{NS}$ & $0,51 \mathrm{NS}$ & $1,81 \mathrm{NS}$ \\
\hline C.V. $(\%)$ & 13,1 & 10,58 & 18,93 & 11,83 \\
\hline Hidrogel & $22,23 \mathrm{a}$ & $3,70 \mathrm{a}$ & $24,08 \mathrm{a}$ & $6,04 \mathrm{a}$ \\
Sem hidrogel & $16,25 \mathrm{~b}$ & $2,85 \mathrm{~b}$ & $18,25 \mathrm{~b}$ & $5,70 \mathrm{a}$ \\
\hline Lâmina 1 & 19,07 & 3,42 & 18,92 & 5,61 \\
Lâmina 2 & 19,73 & 3,27 & 23,16 & 6,05 \\
Lâmina 3 & 18,72 & 3,17 & 18,87 & 5,92 \\
Lâmina 4 & 19,44 & 3,26 & 23,71 & 8,89 \\
\hline${ }^{*}$ significativo a 5\% de probabilidade NS= não significativo a $5 \%$ de probabilidade. Médias seguidas pela mesma letra na coluna, não
\end{tabular}
diferem entre si pelo teste de $\mathrm{F}$, a $5 \%$ de probabilidade.

O crescimento, em termos de altura da planta, é um parâmetro biométrico importante em pesquisas relacionadas à disponibilidade hídrica, produzindo a modificação mais notória do crescimento, especialmente na idade juvenil em que é fácil observar a rapidez da modificação em altura em períodos curtos de tempo (ENCINAS et al., 2005).
Outro bom parâmetro para prognosticar a sobrevivência e qualidade de mudas produzidas em viveiro é o diâmetro de colo, o qual é facilmente mensurável, podendo ser obtido sem a destruição da planta, e é considerado por muitos pesquisadores como sendo um dos mais importantes indicadores para estimar a 
sobrevivência de diferentes espécies florestais após o plantio definitivo (CARNEIRO, 1976).

Para tanto, ao considerar apenas número de folhas, observa-se resposta positiva mostrando que esta variável morfológica é influenciada pelos dois fatores em conjunto, sendo obtida com a utilização de hidrogel e lâmina de água adequada, explicada através do modelo de regressão da função cúbica.

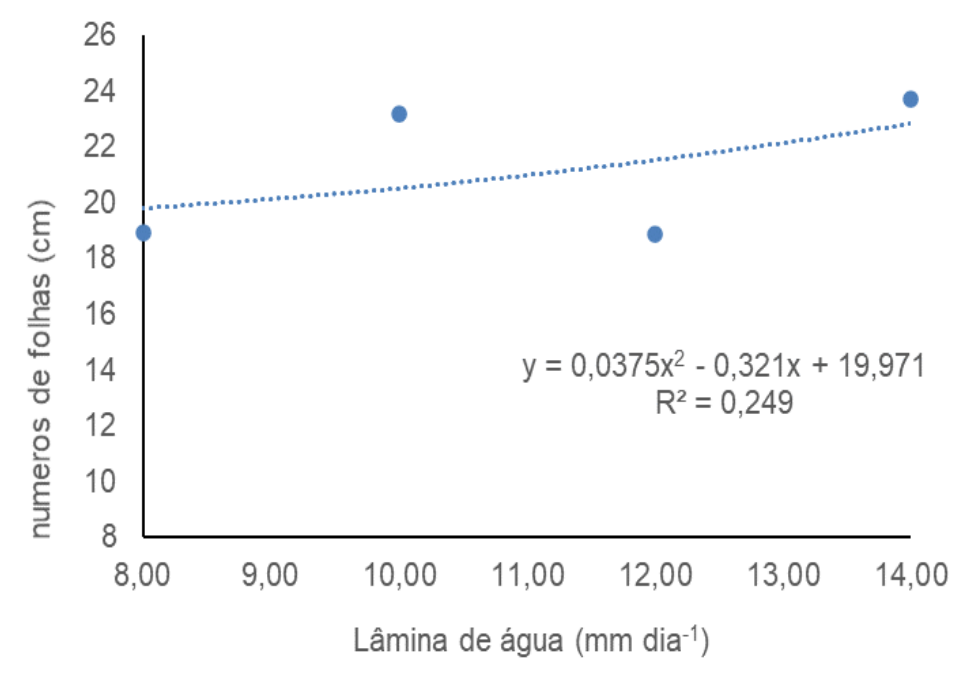

De acordo com o modelo aplicado, há uma alternância conforme se eleva a lâmina, apresentando um melhor resultado ao se utilizar a lâmina diária de $10 \mathrm{~mm}$ e $14 \mathrm{~mm}$. Wilker (2012), obteve resultados semelhantes ao avaliar irrigação no crescimento de mudas de Schinus terebinthifolius, destacando que a lâmina de irrigação a ser utilizada é de $10 \mathrm{~mm}$ diariamente, para um desempenho satisfatório, aliado ao uso racional de água para a produção de mudas da espécie estudada.

Estudos realizados por Santos (2004), corroboram com o exposto acima, ao fazer uso do hidrogel em função de volumes de água, em experimento utilizando mudas de jaqueira, destacou que o tratamento sem a aplicação do polímero hidroretentor se mostrou ineficiente.

Por outro lado, resultados divergentes são apresentados por Felipe et al. (2015), trabalhando com eucalipto demonstram que o uso do hidrogel não resultou diferença significativa, observando-se, que nas avaliações antes da irrigação, tratamentos sem hidrogel apresentaram melhores valores para todas as variáveis analisadas.

De acordo com a Tabela 2, o hidrogel respondeu significativamente a todas as variáveis analisadas, demonstrando que o seu uso acarreta um acréscimo de MSPA, MSR e MST. Os resultados obtidos são semelhantes aos apresentados por Fellipe et al. (2015), em um trabalho realizado com Eucalyptus benthamii, ao se fazer o uso de hidrogel associado ao manejo hídrico, onde demonstram a eficiência do hidrogel como condicionador de solo, no qual, além de aumentar a capacidade de armazenamento de água no solo, as variáveis analisadas (massa seca da raiz e da parte aérea), foram beneficiadas pela adição deste polímero.

Tabela 2- O resumo da análise de variância e os coeficientes de variação das variáveis (MSPA), (MSR), (MST) e (IQD) de mudas de Sapindus Saponária avaliados aos 120 dias após a semeadura são apresentados na Tabela 2.

Em um estudo, avaliando o efeito dos hidrogéis na retenção de água e disponibilidade de nutrientes para Ligustrum lucidum Ait. Taylor e Halfacree (1986), observaram que as plantas cresceram e não necessitam de maior frequência na irrigação, para o tratamento com o polímero, quando comparado com a testemunha. Em contrapartida, Navroski et al. (2016), apresentam resultados distintos, ao testar diferentes doses de hidrogel em Eucalyptus dunnii, observando que houve ganho expressivo de massa seca da parte aérea, em comparação com a ausência de hidrogel ou ao se fazer o uso com doses muito baixas.

Para a variável IQD, observa-se resultados positivos entre os tratamentos com o uso de hidrogel. Segundo Fonseca et al. (2002), o índice de qualidade de Dickson é um bom indicador da qualidade das mudas, pois no seu cálculo são considerados robustez e equilíbrio da distribuição de biomassa na muda, ponderando os resultados de várias características importantes empregadas para avaliação da qualidade. Corroborando com o exposto, Gonçalves (1992) acrescenta que quanto maior o índice de qualidade de Dickson, melhor a qualidade das mudas.

Os resultados da análise acima, mostram ainda que não houve diferença estatística referente às lâminas de água utilizadas. Vale salientar que o 
crescimento das plantas é consequência de uma complexa cadeia de eventos relacionados à produção fotossintética, consumo de fotoassimilados e eficiência de utilização de recursos como água e nutrientes (PRADO et al., 2007; RIBEIRO et al., 2009).
De modo geral, os resultados obtidos com relação ao uso de hidrogel ratificam a informação que a sua adição ao substrato otimiza a disponibilidade de água, acelerando o crescimento das plantas, resultando em mudas com melhor qualidade.

Tabela 2. O resumo da análise de variância e os coeficientes de variação das variáveis (MSPA), (MSR), (MST) e (IQD) de mudas de Sapindus Saponária avaliados aos 120 dias após a semeadura.

\begin{tabular}{|c|c|c|c|c|}
\hline Variáveis & MSPA(g) & $\operatorname{MSR}(\mathrm{g})$ & $\operatorname{MST}(\mathrm{g})$ & IQD \\
\hline Hidrogel & $18,24^{* \star}$ & $11,73^{\text {** }}$ & $19,84^{* *}$ & $13,49^{\star *}$ \\
\hline Lâminas & $1,22 \mathrm{NS}$ & $0,89 \mathrm{NS}$ & $1,37 \mathrm{NS}$ & $1,52 \mathrm{NS}$ \\
\hline$H^{*} L$ & 1,42 NS & $0,65 \mathrm{NS}$ & $0,55 \mathrm{NS}$ & $1,05 \mathrm{NS}$ \\
\hline C. V (\%) & 33,93 & 46,23 & 34,13 & 39,33 \\
\hline Hidrogel & $0,94 \mathrm{a}$ & $1,06 \mathrm{a}$ & $2,00 \mathrm{a}$ & $0,29 a$ \\
\hline Sem hidrogel & $0,56 \mathrm{~b}$ & $0,60 \mathrm{~b}$ & $1,15 b$ & $0,17 b$ \\
\hline Lâmina 1 & 0,83 & 0,91 & 1,74 & 0,27 \\
\hline Lâmina 2 & 0,83 & 0,96 & 1,80 & 0,26 \\
\hline Lâmina 3 & 0,65 & 0,76 & 1,41 & 0,20 \\
\hline Lâmina 4 & 0,65 & 0,68 & 1,36 & 0,19 \\
\hline
\end{tabular}

MSPA = massa seca da parte aérea, MSR = massa seca da raiz, MST = massa seca total, e IQD = Índice de qualidade de Dickson. ${ }^{*}$ Significativo a $5 \%$ de probabilidade, NS = não significativo a $5 \%$ de probabilidade. Médias seguidas pela mesma letra na coluna, não diferem entre si pelo teste de $\mathrm{F}$, a $5 \%$ de probabilidade.

\section{Conclusão}

Nas condições do presente experimento, a incorporação do hidrogel influenciou de forma positiva todas as variáveis analisadas aos 120 DAS, exceto para relação $\mathrm{H} / \mathrm{DC}$.

Em relação às lâminas de água, a mesma não apresentou resultados promissores, se destacando significativamente apenas para a variável número de folhas.

\section{Referências}

BOLFE, E. L. Avaliação da classificação digital de povoamentos florestais em imagens de satélite através de índices de Acurácia. Revista Árvore, Viçosa, v. 28, n. 1, p. 85-90, 2004. Disponível em: https://www.scielo.br/j/rarv/a/93ZWPd7Bh5KxvMyZ9GQP Bqp/?lang=pt\&format=pdf. Acesso em: 25 de ago. 2021.

CARNEIRO, J, G, A. Determinação do padrão de qualidade de mudas de Pinus taeda L. para plantio definitivo. Dissertação (Mestrado em Ciências Florestais), 70 p. Universidade Federal do Paraná, Curitiba-PR. 1976. Disponível em: http://hdl.handle.net/1884/28876. Acesso em: 25 de ago. de 2021.

CARNEIRO, J. G. A. Produção e controle de qualidade de mudas florestais. Curitiba: UFPR/FUPEF, 1995. 451 p.

DIAS, E. S.; KALIFE, C.; MENEUCCI, Z. R. H.; SOUZA, $P$. D. Produção de mudas de espécies florestais nativas. Campo Grande, MS: Ed. UFMS, 2006. Disponível em: https://www1.ufrb.edu.br/biblioteca/documentos/category/ 18-sementes-e-viveiros-florestais?download=222: manualproducao-de-mudas-de-especies-florestais-nativas.

Acesso em: 24 de ago de 2021

DICKSON, A.; LEAF, A. L.; HOSNER, J. F. Quality appraisal of white spruce and white pine seedling stock in nurseries. Forestry Chronicle, v. 36, p. 10-13, 1960. Disponível em: https://doi.org/10.5558/tfc36010-1. Acesso em: 24 de ago. de 2021.
ENCINAS, J. I.; SILVA, G.F.; PINTO, J.R.R. Idade e crescimento das árvores. Comunicações Técnicas Florestais. Brasília: UNB, 47 p. v.7, n.1, 2005.

FELIPPE, D.; NAVROSKI, M. C.; FRIGOTTO, T.; MENEGUZZI, A.; MAZZO, M. V. influência do hidrogel e do manejo hídrico na massa seca de mudas Eucalyptus benthamii maiden. III Congresso Brasileiro de Eucalipto, 2015. Vitória/ES. Disponível em: http://dx.doi.org/10.5380/rf.v46i2.43920. Acesso em: 25 de ago. de 2021.

FERREIRA, D. F. Sisvar: a computer statistical analysis system. Ciência e Agrotecnologia, v. 35, n. 6, p. 10391042, 2011. Disponível em: https://www.scielo.br/j/cagro/a/yjKLJXN9KysfmX6rvL93TS h/?lang=en. Acesso em: 25 de ago. de 2021.

FONSECA, É. D. P.; VALÉRI, S. V.; MIGLIORANZA, É.; FONSECA, N. A. N.; COUTO, L. Padrão de qualidade de mudas de Trema micrantha (L.) Blume, produzidas sob diferentes períodos de sombreamento. Revista árvore, v. 26, n. 4, p. 515-523, 2002. Disponível em: https://doi.org/10.1590/S0100-67622002000400015. Acesso em: 24 de ago. de 2021.

GOMES, J. M.; PAIVA, H. N. Viveiros florestais (propagação sexuada). Viçosa: Editora UFV, 2004.116 p. (Caderno didático,72). Disponível em: https://www.editoraufv.com.br/produto/viveiros-florestaispropagacao-sexuada-serie-didatica/1110307. Acesso em: 25 de ago. de 2021.

GONÇALVES, M. G. Crescimento e acúmulo de nutriente e temperatura de copa em 5 espécie de Eucalyptus ssp. sob dois regimes hídricos. 1992. 84 f. Dissertação (Mestrado em Silvicultura) - Universidade Federal de Viçosa, Viçosa MG.

GORDIN, C. R. B.; SCALON, S. P. Q.; MASETTO, T. E. Disponibilidade hídrica do substrato e teor de água da semente na germinação de niger. Pesquisa Agropecuária Tropical. v.45, n.3, p. 312-318, 201. Disponível em: 
https://www.revistas.ufg.br/pat/article/view/35337. Acesso em: 25 ago. 2021.

LARCHER, W. Ecofisiologia vegetal. São Carlos: Rima Artes e Textos, 2004. $531 \mathrm{p}$.

MORAES, W. W. C.; SUSIN, F.; VIVIAN, M. A.; ARAÚJO, M. M. Influência da irrigação no crescimento de mudas de Schinus terebenthifolius. Pesquisa Florestal Brasileira.v.32, n.69, p.23-28. 2012. Acesso em: https://pfb.cnpf.embrapa.br/pfb/index.php/pfb/article/downl oad/313/243/2824. Acesso em: 24 de ago. de 2021.

NAVROSKI, M. C. Efeito do volume do tubete e doses de fertilizantes no crescimento inicial de mudas de Eucalyptus dunnii Maiden. Agrarian, v. 9, n. 31, p. 26-33, $2016 . \quad$ Disponível em: https://ojs.ufgd.edu.br/index.php/agrarian/article/viewFile/3 160/3634. Acesso em: 25 de ago. de 2021.

PRADO A.K.S. MACHADO E.C. MEDINA C.L. MACHADO D.F.S.P. MA AFERA P. F florescimento e frutificação em laranjeiras com diferentes cargas de frutos, submetidos ou não a irrigação. Bragantia, Campinas, v. 66, p. 173-182, 2007. Disponível em: https://doi.org/10.1590/S000687052007000200001. Acesso em: 25 de ago. de 2021.

RIBEIRO, V. V.; BRAZ, M. D. S. S.; DE BRITO, N. M. Tratamentos para superar a dormência de sementes de tento. Biotemas, Florianópolis, v. 22, n. 4, p. 25-32, 2009. Disponível em: https://doi.org/10.5007/2175 7925.2009v22n4p25. Acesso em: 25 de ago. de 2021.

SANTOS, P.L.; FERREIRA, R.A.; ARAGÃO, A.G.; AMARAL, L.A.; OLIVEIRA, A.S. Estabelecimento de espécies florestais nativas por meio de semeadura direta para recuperação de áreas degradadas. Revista Árvore, Viçosa, v. 36, n. 2, 2012. Disponível em: https://www.scielo.br/j/rarv/a/bFBZSRgHbpxwJR9bMMVqs sp/?lang=pt\&format=pdf. Acesso em: 25 de ago. de 2021.

SCALON, S.P.Q.; SCALON FILHO, H.; RIGONI, M.R. VERALDO, F. Germinação e crescimento de mudas de pitangueira (Eugenia uniflora L.) sob condições de sombreamento. Revista Brasileira de Fruticultura, v.23, n.3, p.652-655, 2001.2 Disponível em: https://doi.org/10.1590/S0100-29452001000300042.

Acesso em: 24 de ago. de 2021.

SILVA, A.; DE SOUZA FILHO, E. E.; DA CUNHA, S. B. Padrões de canal do rio Paraguai na região de Cáceres (MT). Revista Brasileira de Geociências, v. 38, n. 1, p. 167-177, 2008. Disponível em: http://www.ppegeo.igc.usp.br/index.php/rbg/article/view/75 75. Acesso em: 24 de ago. de 2021.

SILVA, C. R. A., RIBEIRO, A., OLIVEIRA, A. S. DE., KLIPPEL, V. H., BARBOSA, R. L. P. Desenvolvimento biométrico de mudas de eucalipto sob diferentes lâminas de irrigação na fase de crescimento. Pesquisa Florestal Brasileira: Brazilian Journal of Forestry Research, v.35, n. 84, p.381-390, 2015. Disponível em: https://doi.org/10.4336/2015.pfb.35.84.897. Acesso em: 25 de ago. de 2021.

SOUZA, V. C.; LORENZI, H. Botânica Sistemática. São Paulo: Nova Odessa, p. 640. 2005. Disponível em: https://searchworks.stanford.edu/view/6525394. Acesso em: 24 de ago. de 2021.
TAYLOR, K. C.; HALFACRE, R. G. The effect of hydrophylic polymer on média water retention and nutrient availability to Ligustrum lucidum. HortScience, Alexandria, v. 21, n. $5,1159-1161,1986$.

WENDLING, I.; DUTRA, L. F. Produção de mudas de eucalipto por estaquia e mini estaquia. In: WENDLING, I.; DUTRA, L. F. Produção de mudas de eucalipto. Colombo: Embrapa Florestas, 2010. p. 50-80. Disponível em: https://livimagens.sct.embrapa.br/amostras/00085650.pdf. Acesso em: 24 de ago. de 2021.

WILKER, W. C. M.; SUSIN. F.; ALAN. M. V.; MACHADO. M.A. Influência da irrigação de mudas Schinus terebinthifolius. Embrapa Florestas, 2012. Disponível em: https://pfb.cnpf.embrapa.br/pfb/index.php/pfb/article/view/3 13. Acesso em: 25 de ago. de 2021. 